\title{
Oral Biofilm and Prosthetic Materials
}

\author{
(1) Simge Tașar Faruk¹, (1) Meryem Güvenir²
}

1Department of Prosthodontics, Near East University Faculty of Dentistry, Nicosia, North Cyprus

2Department of Medical Microbiology, Cyprus Health and Social Sciences University Faculty of Medicine, Güzelyurt, North Cyprus

\section{Abstract}

Oral microbiota is altered with the constituents of prosthetic biomaterials and dental restorations which are used for rehabilitation. As a result, such composition may have negative effects on the health of cavum oris and prosthetic biomaterials. The said oral condition is a common dental disorder formed by bacterial biofilms due to uncertain reasons. Problems caused by these biofilms have a close relationship with the kind of restoration carried out or material used. In relation to biomaterials, factors such as surface roughness, surface energy, and chemical structure affect microbiologic composition and biofilm accumulation. Recently, the use of restorative materials which inhibit the accumulation of dental plaque have become common. In consideration of the many problems related to biofilm accumulation on dental materials, the aim is to improve the prosthetic materials used to replace tissues while ameliorating oral health.

Keywords: Dental plaque, biofilm, denture, Candida albicans, Streptococcus mutans

\section{INTRODUCTION}

The oral cavity is the home to the hundreds of bacteria, fungi and viruses. These microorganisms are cross-linked with each other and form biofilms on the various surfaces of the oral cavity. ${ }^{1}$ The microorganisms which form dental biofilm usually have harmless relationship with the host, although they have regular exposure to environment perturbations and host defense factors. ${ }^{2}$ Although the biomaterials for the restorative appliances are accustomed to biofilm formation in the oral cavity, they are a major cause of periodontal diseases, tooth decay, and gingivitis. ${ }^{3}$

How does the biofilm formation occur in the oral cavity? What factors can effect this formation? How does the biofilm attach to the restorative materials and what is the treatment choice? This review briefly discusses recent articles to the answer these questions.

\section{Biofilm}

The opinion of that microorganisms are live together and can do the biofilms is first characterized by Antonie van Leeuwenhoek, who first reported "microbial aggregation" on the surface of teeth, and Louis Pasteur. ${ }^{4}$ Biofilm is a structured league attached to a living or inert surface assemble with microorganism adhering to each other and produced extracellular polymeric elemets. ${ }^{5}$ The matrix saturate the biofilm with a range of attributes such as antibiotic resistance, storage of extracellular enzymes, nutrient capture, gradient formation. So that, the matrix is extremely responsible for the structure of biofilm. ${ }^{6}$ Biofilm could be formed in two way; (i) formed by single bacteria species called as monofilms or (ii) formed by more than one bacteria species called as multifilms. ${ }^{7}$

Dental plaque is an important example of the polymicrobial biofilm that form on the surfaces of teeth and, can lead to dental caries, periodontitis or other oral diseases. ${ }^{8}$

\section{Oral Biofilm}

Estimated more than 700 different bacterial species have been reported in the oral cavity of human saliva $\left(10^{8}\right.$ to $\left.10^{9} \mathrm{CFU} / \mathrm{mL}\right)$, and a few of

To cite this article: Tașar Faruk S, Güvenir M. Oral Biofilm and Prosthetic Materials. Cyprus J Med Sci 2022;7(6):712-717

ORCID IDs of the authors: S.T.F. 0000-0002-9805-4327; M.G. 0000-0002-9702-9947. 
bacteria adhere to the teeth and cause the dental biofilm. ${ }^{9}$ The oral biofilm includes many bacteria and cell-free organelles entrenched in an extracellular matrix. The extracellular matrix support the microenvironment for the immobilized bacteria. ${ }^{10}$ Dental plaque is characterized by its huge diversity (>700 species) and high cell density, which assist the progress of organisms to cross-talk each other., ${ }^{11}$ Crosstalked between bacteria is important for initial colonization to start forming the biofilm. If the bacteria do not be successful to retain on the tooth surface, the bacteria are cleaned by the mouth fluid. If the bacteria get success to adhere to surfaces, they start to organize other multispecies to form a dental plague (Figure 1). Cell-cell interaction between genetically specific cells can also take place in suspension called as co-aggreation. Oral bacteria have many co-aggreation partner (Table 1). The studies indicated that initial colonizers are Streptococci spp. and Actimomyces spp. ${ }^{12}$ Studies indicated that many types of adhesion are related with the process of dental biofilm such as surface tension and chemical interactions. Also, studies reported that the most dominant group of the adhesion for supragingival bacteria is sucrosedependent adhesion. ${ }^{13}$

The dental biofilms also has another comminication system called as quarum sensing. This system was based on quarum signal molecules like autoinducer- 1 and autoinducer- 2 which have an important role into both structure and virulence of the biofilm. ${ }^{14}$

\section{Mechanisms of Biofilm Formation}

Biofilm development takes place by five steps: (1) adhesion to tissues; (2) growth; (3) maturation distinguished by metabolic and genetic microbial trades, growth regulated by quorum-sensing molecules and antimicrobial peptides; (4) tissue invasion/destruction; and 5) surface detachment. ${ }^{15}$ According to these stages, three-dimensional structure

\begin{tabular}{|l|}
\hline Table 1. The list of the oral bacterial colonizer on the tooth \\
\hline Streptococcus oralis and Streptococcus sanguinis \\
\hline Streptococcus mitis \\
\hline Streptococcus gordonii \\
\hline Capnocytophaga ochraccea \\
\hline Propionibacterium acnes \\
\hline Haemophilus parainfluenzae \\
\hline Prevotella loescheii \\
\hline Veillonella spp. \\
\hline Actinomyces oris and Actinomyces naeslundii \\
\hline Eikenella corrodens \\
\hline Actinomyces israelii \\
\hline Capnocytophaga gingivalis \\
\hline Capnocytophaga sputigena \\
\hline Fusobacterium nucleatum \\
\hline Prevotella denticola \\
\hline Aggregatibacter actinomycetemcomitans \\
\hline Eubacterium spp. \\
\hline Treponema denticola \\
\hline Tannerella forsythia \\
\hline Porphyromonas gingivalis \\
\hline Prevotella intermedia \\
\hline Selenomonas flueggei \\
\hline
\end{tabular}

which is formed by microorganisms are seperated by water channels that allow the entry of nutrients, oxygen and discharge the waste products. ${ }^{16}$ In the first step, bacterial cells consume the van der Waals forces to join the surface. ${ }^{17}$ In step one, cell attachment is still reversible, but in second step; the cells attach themselves more strongly to produce the exopolymeric material. In step three, micro-colonies are produced, and the biofilm become to mature. In step four, included more maturation, and the biofilm evolve into a three dimensional structure. In step five the biofilm distribute the cells. ${ }^{18}$

The attachment step could be classified into two process: initial reversible attachment and irreversible attachment. ${ }^{19}$ The irreversible attached biofilm can allow physical or chemical forces. ${ }^{20}$ In the initial attachment, flagella and type IV pili-mediated motilities are important. Flagellas are imporant between cells and surface interactions. Also, type IV pilimediated twitching motilities are important for the attached cells to aggregate and form microcolonies. ${ }^{21}$ Different researches evaluated the effect of biofilm accumulation related to surface characteristics like surface free energy, roughness, topography and chemical structure of the dental biomaterials. Surface characteristics and chemical composition was found effectiveon the topography and surface energy as well as the type of restoration. ${ }^{22}$

\section{Impacts of Physical and Chemical Properties of Different Prosthetic Restorations and Biomaterials on Dental Biofilms}

\section{Surface Energy}

It is noted that polished surfaces have lower surface energy. Dental materials, except ceramics, mostly have a higher surface energy compared to enamel which cause higher risk of biofilm accumulation. It is a known fact that changes in surface roughness (SR) generally influenced the surface energy. ${ }^{22}$

\section{Surface Roughness}

It has been shown that nonpolished surfaces tend to have more oral biofilm accumulation than polished one. Although, the surfaces which have roughness higher than the threshold value which is $0.2 \mu \mathrm{m}$, may cause a concurrent increase in biofilm development, however there was no decrease in adhesion of bacteria below the threshold. ${ }^{23}$ Also, the deeper and larger fossas and grooves may increase the area in contact and become more suitable places for bacterial colonies and biofilm accumulation. Following the accumulation, bacteria will defend against shear forces (washing and brushing) during first reversible bonding which will cause irreversible and powerful bond. Thus, it is hard to remove colonies on the irregular surfaces and this will followed by the development of matured biofilm. ${ }^{24}$ Whereas, enhancing implant osseointegration, the SR is indicated as the basic requirement for induction of biofilm growth. Increased SR value may be the reason for growing in bacterial cells exponentially and enable biofilm accumulation regarding the components of the biofilm. On the other hand, a study approved that implants having irregular surfaces are not prone to fail, and the results indicated that similar microbiologic composition for titanium with various SR. ${ }^{23}$

\section{Chemical Composition}

The chemical structure of the biomaterial may have an effect on the accumulation of bacteria due to chemical attachment of proteins and microorganisms which can attach chemically or attract to constituents in the material, via bonds or interactions. So, the chemically formed 
interaction between biomaterial and microorganisms can alter the surface characteristics. ${ }^{22}$

\section{Antibacterial Properties of Restorative Material}

It was found that restorative materials like amalgam, gold alloys which flow ions or glass ionomer cement which flow flouride, inhibite formation or maturation of bacteria. ${ }^{25}$

\section{Dental Restorations}

Prosthetic materials and different types of restorations can influence biofilm formation in different ways.

\section{Crowns and Bridges}

The joining line for the tooth and restoration may cause problems, since it is not possible to construct fixed prosthesis with ideal adaptation. Irregular, short or improper margins are formed at gingival margin, and this makes mechanic elimination of biofilms harder and change chemical equilibrium for biofilm in this area. ${ }^{26}$ In addition, the fossas or edges will increase ormation of plaque and make the mechanical elimination of plaque harder. ${ }^{22}$ Fixed partial dentures are generally fabricated by ceramics, metals or combinations. So, assesment of different types of materials used in fabrication of fixed restorations is essential.

\section{Ceramics}

Ceramic has smooth and polished surface which can be easily cleaned. Biofilm accumulates on irregular surfaces more than regular surfaces. It is reported that biofilms on ceramics are thin and highly viable. That is why, relative to other materials used in dentistry, ceramics are shown to promote to decrease adhesion of bacteri and biofilm accumulation. ${ }^{26}$ Also it is noted margins of ceramic restorations with few tiny defects caused by machining procedures will lead retaining of more deposition and bacteria than a smooth finish line. ${ }^{22}$

Various kinds of ceramics may cause bacterial adhesion with different rates. Hahnel et al. ${ }^{27}$ investigated surface properties of dental ceramics belonging to various ceramic groups, and correlated the outcomes to the first adherence of oral streptococcal strains. The lithium disilicate glass ceramic had the highest SR (Ra); the lowest values were found for the glass ceramic, the partially sintered zirconia and the hipped zirconia ceramic. It is concluded that dental ceramics have difference in terms of Ra, free energy and initial streptococcal adhesion; although, correlation between surface characteristics and adherence of streptococcus were poor.

Finishing and polishing methods may cause difference on biofilm formation. In a study ${ }^{28}$ the effect of several surface finishing and polishing techniques on SR and Streptococcus mutans (S. mutans) adherence to resins and ceramic (VITABLOCS Mark II), was examined. As result, ${ }^{28}$ SR were found significantly different according to the prosthetic material and surface treatments. On the other hand, no significance for interaction was noted between restorative materials and surface treatments. The highest SR values were found for indirect composite and it is followed by ceramic group. The lowest vital S. mutans adherence was observed in ceramic samples. So it can be said there is a positive correlation between SR and the vital S. mutans adhesion. Significant difference between bacterial adhesion of tested materials indicates that chemical composition of surface of the restorative material has important impact on bacterial adhesion. In contrast, porcelain restorations with glazing is indicated as the ideal. It is reported that surface with glazing may not be the smoothest all the time, and polished surface would be required for forming a smoother surface. Kawai et al..$^{29}$ approved glazed surface was always not the smoothest, according to Ra values which more plaque was accumulated on surfaces with glazing, in comparison to surfaces with polish (120 or 600 grit abrasive paper). This indicates that surface with glazing would not be clinically favourable biologically. Glaze may create an wavy and nonuniform surface that generally has irregularities, leading more bacterial adherence. Whereas polished surfaces were shown having voids and cracks on subsurface of ceramic, these defects have no effect on Ra or the quantity of plaque accumulation. As a result, samples polished with diamond pastes were found useful in forming a smoother surface which can avoid plaque accumulation. Other researchers ${ }^{30}$ evaulated the effect of polishing on ceramic on initial oral biofilm accumulation for zirconium by using a scanning electron microscope after 20 minutes and 1 hour. Deposition of granular aggregations were found on all the samples for the two consecutive analyzes. Granular aggregates adhere stronger on nonuniform regions, and increase in thickness is observed after 1 hour. Bacterial morphology in any time of the research was not significantly different. Irregularities on surface of samples with glazing was found more than polished sample and presented larger tendency to dental biofilm accumulation.

\section{Metal Alloys}

Various alloys used in dental practice are basicly gold, nickel chrome and titanium. Prosthetic appliances are fabricated with inert alloys with polished surfaces to avoid the accumulation and attraction of micro-organism not to cause biofilm, ${ }^{26}$ however some alloys' tendency is high to bacteria compared to others. It shows that some bacteria are attracted to electrical charges in some alloys. Alloys which contain and release copper and silver were noted to have higher antimicrobial activity than some base metal alloys. Eluates of the metals may have an effect on microorganisms. The mercury leaching in very small amounts have a bacteriostatic effect. ${ }^{22,26}$ The relationship regarding adhesion of Streptococcus mitis (S. mitis), S. mutans, Streptococcus oralis (S. oralis) and Streptococcus sanguinis (S. sanguinis) on precious and non-precious alloys used in dentistry was examined by Grivet et al. ${ }^{31}$ and bacterial adherence was found highest for the high gold-contaning alloy, and lowest for the non-precious alloy.

\section{Cements}

Gap between the teeth and the restoration is filled with dental cement. There may be few milimeters gap which is in interaction with oral liquids. This space may create ideal enviroment for bacterial adhesion and colonization. It is obvious, the existence of biofilm is only one of the features which can induce surface deterioration, other impacts are acidic fluid intake, temperature changes, or existence of liquid medium. It is noted that roughness of resins having larger filler molecules became lesser noticeably after biofilm maturation. ${ }^{32}$

In addition, effect of false, improper mixing ratios of various luting systems on adherence of $S$. mutans were evaulated. ${ }^{33}$ Various tested luting cements displayed significantly different potentially in S. mutans adherence. Variations from recommended luting agent ratios cause significant alterations for quantity of adhered Streptococci. 


\section{Dentures}

Polymers used in denture construction, such as acrylic resins, have more porous structure and defects on surface compared to metallic and ceramics restorative materials. Pores will be fulfilled by humidness which cause ideal incubation environment for some microorganisms. Biofilm on polymeric substances grows faster and is harder to elimiate completely. Acidic remnants caused by bacteria will make the surface irregular, that will led complications in elimination of biofilm.22

\section{Acrylic Resin (Denture Base)}

New areas for biofilm accumulation is formed by removable dentures, thus these areas cause increase in quantity of biofilm appreciably. An increased amount of of microorganisms changes the ecology of the cavum oris that may alter equilibrium between harmful and useful microorganisms in oral cavity. The mucosa which is directly in contact with the dentures are the most influenced sites, however the other soft tissues in the oral cavity are involved, too. ${ }^{22}$ In addition, yeasts especially candida species are associated with denture base resins. Different candida species with some bacteria are indicated that are working synergistically for attaching to denture base resin or to each other. ${ }^{26}$ Fungal species, like Candida albicans (C. albicans), can grow with chemical or physical changes. Proliferations of Candida results in response by inflammation on the mucosa beneath the biofilm which is called "denture stomatitis". ${ }^{22}$ Biofilm consisting yeasts are shown to be hard to eliminate associated with high adhesion capacity, because this ability has a close relationship with micro-porous structure of resin. ${ }^{26}$

The hard acrylic prosthesis may cause injuries and ulcerations on mucosa if dentures are not well-fitted. These ulcerated regions are habits for fungis and bacteria leading inflammatory response and pain. In addition, rests are attractive places for microorganism colonization. ${ }^{22}$ Thus, all rules related denture should be obeyed in every single step of construction for creating dentures with gold standard.

\section{Denture Liners}

The liner biomaterials are made of self curing acrylic, polyvinyl siloxane, or acrylic including plasticizers. These prosthetic materials have porous structure than conventional acrylic and have more complications with inflammation caused by fungis. Dentist should be suspectible for $C$. albicans adhesion while using soft liners. Some soft denture liners, like polyamides have possibly lesser tendency for biofilm accumulation in comparison to acrylic resins related to lesser porosities. ${ }^{22,26}$ In an study ${ }^{34}$ SR were measured and adherence of $C$. albicans were studied before and after aging procedure of dentures relined with 3 different denture liners. The stimulated saliva was used for assesing effect of aging process on adherence. Non-aged and uncoated samples had not been found significantly different, but aged and uncoated soft liners were noted to have higher degree of $C$. albicans adhesion. Also, non-aged and coated liner samples had not been indicated as significantly different, on the other hand aged and coated biomaterials had higher affinity to C. albicans adhesion. It can be concluded that the usage of soft liners with uniform surface decrease the risk of $C$. albicans adhesion.

\section{Dental Implants}

There will always be gaps and crevices between small components of implant that are fixed together by small screw, forming a "greenhouse" for bacterias. Pathogenic bacteria in these areas may lead inflammatory response in the bone or affects osseointegration negatively. Also it is noted that rough titanium surface is adequate nish for fast bacterial growth and adhesion that titanium abutment usage is common in implant rehabilitation. It was concluded that surface energy and SR is directly proportional with the bacterial adhesion. So it can be said that plaque accumulation is more on titanium abutments compared to natural teeth that is why titanium have high surface energy. This disadvantage of titanium can be eliminated by good oral hygiene. ${ }^{35}$

Other alternative to titanium is zirconia abutments. Difference between adhesion tendencies of bacteria and several materials were reported. Researchers had compared the rates of bacteria on titanium and zirconium oxide samples. The test samples coated with bacteria on zirconia specimens were found significantly lesser in comparison to titanium samples. The results demonstrated that zirconium oxide is a good biomaterial for fabrication of implant abutments having lower colonization potential. ${ }^{36}$ In a study, ${ }^{37}$ polished partially stabilized zirconia (PZ), titanium blasted with zirconia (TBZ), TBZ then etched (TBZA), and polished titanium (PT- control) were analyzed by help of scanning electron microscope and profilometry. The zirconia and TBZ surface (TBZ surface) was found effective on titanium superiorly by decreasing the adherence of bacteria following pellicle coverage. Also, modified titanium with zirconia had been found to have same surface characteristics of pure zirconia in decreasing adherence of bacteria.

\section{Chemical and Biological Methods to Control Oral Biofilms}

Choosing proper mechanical and biological treatment options or usage of antimicrobial agents may be useful for avoiding biofilm formation and accumulation.

\section{Acrylic Resins}

Polishing and finishing techniques should be used and repeated regularly for achieving a SR under the threshold on polymers used in dentistry. ${ }^{22}$ Also, modifying resins in alternative form of polyethylene, titanium dioxide coating and using denture cleansers were approved to be discouraging on the biofilm accumulation. ${ }^{26}$ Inhibiting $C$. albicans on resins have significant role for prevention of denture stomatitis. The biological acceptance of a newly produced dental biomaterial having antifungal properties was examined by researchers. ${ }^{38}$ The results demonsrated which PMMA-silver nanoparticles have significant reducing effect on $C$. albicans adhesion and have no effect on metabolism or proliferation. Even though the solutions containing silver nanoparticles had antifungal activity, Øilo and Bakken ${ }^{22}$ noted no impact on C. albicans adhesion and biofilm accumulation following the addition of particles into resin. But, long term effecs of surface coatings or slow releasing molecules are uncertain. Coatings may be abrased, their roughness may increased and mechanical characteristics may decrease with time. So, further investigation is needed. Also, cleansing agents like Klorhex and Fittydent have been proposed as effective in prevention of Candida colonization rate on denture surfaces. ${ }^{39}$

\section{Resin Composites}

Decreased polymerization shrinkage of resins is thought to have lower rate of microleakage and thus the risk of secondary caries is reduced..$^{22}$ So, polymerization procedure should be performed ideally. On the other hand, several techniques for eliminating biofilm on biomaterials used in dentistry can be listed as addition of zinc oxide nanoparticles blend and/or chlorhexidine gluconate in some restorative biomaterials for enhancing the antibacterial activation and reducing growth of bacteria responsible from biofilm formation. ${ }^{40}$ 


\section{CONCLUSION}

Dental biofilm is a complex, organized bacterial community. So, elimination of microorganism from oral soft and hard tissues are a struggle either for patients or dentists. Although biofilm formed on dentures seems harmless, it may cause complex problems. Thus, dentist should be take in consideration the possibility of biofilm formation and should be careful in selection of restorative material and surface treatments for minimizing bacterial adhesion. Also patient should be informed about biofilm formation and routine oral hygiene methods to avoid plaque accumulation. Although the dental biofilm can not be removed it can be decreased with mechanical and chemotherapeutic oral hygiene methods. Further in situ studies are much needed to clarify, the role and mechanism of each surface parameter on oral biofilm formation and also especially antimicrobial strategies should be disscussed in upcoming researches.

\section{MAIN POINTS}

- Dental plaque is organized and this organized mass forms oral biofilm. Microorganisms that formed dental biofilm generally have harmless relation with host. But this oral condition may be changed negatively by environmental pertubations and restorative materials used for dental rehabilitation.

- Physical and chemical properties of prosthetic restorations, biomaterials and also interactions between them have strong impact on the formation of dental biofilm. So, the dentist should take in account either the composition of dental material or type of restoration while assesing treatment plan.

- There are several chemical and biological techniques which are used in controlling oral biofilm accumulation. Antibacterial agents usage, modification of polymers or titanium dioxide coating are some of the alternative methods used for minimizing plaque formation and thus oral biofilm growth. However, there is no enough data indicating ideal prosthetic material and technique which is effective for inhibition of bacterial adhesion.

Therefore, there is need for further researches based on development of antibacterial agents, techniques and prosthetic materials with ideal physical, microbiologic and chemical properties.

Peer-review: Externally peer-reviewed.

\section{Authorship Contributions}

Concept: S.T.F., M.G., Design: S.T.F., M.G., Supervision: S.T.F., M.G., Fundings: S.T.F., M.G., Materials: S.T.F., M.G., Data Collection and/ or Processing: S.T.F., M.G., Analysis and/or Interpretation: S.T.F., M.G., Literature Search: S.T.F., M.G., Writing: S.T.F., M.G., Critical Review: S.T.F., M.G.

\section{DISCLOSURES}

Conflict of Interest: No conflict of interest was declared by the authors.

Financial Disclosure: The authors declared that this study had received no financial support.

\section{REFERENCES}

1. Kuramitsu HK, He X, Lux R, Anderson MH, Shi W. Interspecies interactions within oral microbiol communities. Microbiol Mol Biol Rev. 2007; 71(4): 65370

2. Coyte KZ, Schluter J, Roster KR. The ecology of the microbiome: networks, competition and stability. Science. 2015; 350(6261): 663-6.

3. Maddi M, Scannapieco FA. Oral biofilms, oral and periodontal infections, and systemic disease. Am J Dent. 2013; 26(6): 249-54.

4. Hoiby N. A short history of microbiol biofilms and biofilm infections. APMIS 2017; 125(4): 272-5.

5. Flemming HC, Wingender J, Szewyk U, Stainberg P, Rice SA, Kjelleberg S Biofilms: an emergent form of bacterial life. Nat Rev Microbiol. 2016; 14(9): 563-75.

6. Liaqat I, Liaqat M, Ali S, Al NM, Haneef U, Mirza SA, et al. Biofilm formation, maturation and prevention: A review. J Bacterial Mycol. 2019; 6(1): 1092.

7. Maksimova YuG. Microbiol biofilms in biotechnological process. Appl Biochem Microbiol. 2014; 50: 750-60.

8. Yu OY, Zhaols MG, Mei ML, Lo Ec, Chu CH. Dental biofilm and labarotory microbial culture models for cariology research. Dent J. 2017; 5(2): e21.

9. Larsen T, Fiehn N. Dental biofilm infections-an update. APMIS. 2017; 125(4): 376-84.

10. Steinberg D. Handbook of Bacterial Adhesion: Principles, Methods and Applications (Eds: Y.H. An, R.J. Friedman). Humana Press, Totawa NJ, 2000, p. 353-70.

11. Overmann PR. Bofilm: a new view of plaque. JCDP. 2000; 18-29.

12. Dige I, Raarup MK, Nyengaard JR, Killian M. Nyvad B. Actinomyces naeslundii in initial dental biofilm formation. Microbiology. 2009; 155 (7); 2116-26.

13. W.F. Lilijemark C, Bloomquist. Crit Rev Oral Biol Med. 1996; 7: 180-98.

14. Bentinez-Paez A, Belda-Ferre P, Simon-Soro A, Mira A. Microbiota diversity and gene expression Dynamics in human oral biofilms. BMC Genomics. 2014; 15: 311-23.

15. Park SJ, Han K_H, Park JY, Choi SJ, Lee KH. Influence of bacterial presence on biofilm formation of Candida albicans. Yonsei Med J. 2014; 55(2): 449-58.

16. AndreLuis Souza dos Santos, Galdinı ACM, de Mello TP, Ramos LS, Branquinha $\mathrm{MH}$, Bolognese $\mathrm{M}$. What are the advantages of living in a commnity? A microbial perspective. Mem Inst Oswaldo Cruz. 2018; 113(9): e18021.

17. MSU, Manotana State University 2016. A biofilm primer: how biofilms form. Biofilms online.Available at http://www.biofilmsonline.com/cgi-bin/ Biofilmsonline/edhowprimer.htmı.

18. Hall-Stooodley L and Stoodley P.Biofilm formation and the transmission of uman pathogens. Trends Microbiol. 2005; 13(1): 3-10.

19. Renner LD, Weibel DB. Physicochemical regulations of bioflim formaiton MRS Bull. 2011; 36(5): 347-55

20. Sutherland I. Biofilm exopolysaccharides: a strong and sticky framework Microbiology. 2001; 147(1): 3-9.

21. O'Toole GA, Kolter R. Flageller and twiching motility are necessary for Pseudoonas aeruginosa biofilm evelopment. Mol Microbiol. 1998; 20(21): 295-304.

22. Øilo M, Bakken V. Biofilm and Dental Biomaterials. Materials. 2015; 8: 2887 900 .

23. Hao Y, Huang I, Zhou X, Li M, Ren B, Peng, et al. Influence of Dental Prosthesis and Restorative Materials Interface on Oral Biofilms International Journal of Molecular Sciences Int J Mol Sci. 2018; 19: 3157. 
24. Cazzaniga G, Ottobelli M, Ionescu A. Surface properties of resin-based composite materials and biofilm formation $A$ review of the current literature. Am J Dent. 2015; 28: 313-20.

25. Bani M, Öztaș N. Cam iyonomer içerikli farklı restoratif materyallerin yüzey pürüzlülüklerinin değerlendirilmesi. Acta Odontologica Turcica. 2013; 30(1): 13-7.

26. Al Moaleem MM, Dorout IA, Elamin EF, Mattoo KA, Ghazali NAL. Biofilm Formation on Dental Materials in the Presence of Khat: Review. JSM Dent. 2017; 5(2): 1087.

27. Hahnel S, Rosentritt M, Handel G, Bürgers R. Surface characterization of dental ceramics and initial streptococcal adhesion in vitro. Dent Mater. 2009; 25: 969-75.

28. Aykent F, Yondem I, Ozyesil AG, Gunal SK, Avunduk MC, Ozkan S. Effect of different finishing techniques for restorative materials on surface roughness and bacterial adhesion. J Prosthet Dent. 2010; 103(4): 221-7.

29. Kawai K, Urano M, Ebisu S. Effect of surface roughness of porcelain on adhesion of bacteria and their synthesizing glucans. J Prosthet Dent. 2000; 83: $664-7$.

30. Scotti R, Zanini Kantorski K, Scotti N, Monaco C, Valandro LF, Bottino MA Early biofilm colonization on polished- and glazed-zirconium ceramic surface. Preliminary results. Minerva Stomatol. 2006; 55: 493-502.

31. Grivet M, Morrier JJ, Benay G, Barsotti O. Effect of hydrophobicity on in vitro streptococcal adhesion to dental alloys. J Mater Sci Mater Med. 2000; 11: 637-42.

32. Hannig C, Hannig M. The oral cavity--a key system to understand substratumdependent bioadhesion on solid surfaces in man. Clin Oral Investig. 2009; 13(2): 123-39.
33. Buergers R, Hahnel S, Reischl U, Mueller R, Rosentritt M, Handel G, et al. Streptococcal adhesion to various luting systems and the role of mixing errors. Acta Odontol Scand 2009; 67(3): 139-45.

34. Bal BT, Yavuzyilmaz H, Yücel M. A pilot study to evaluate the adhesion of oral microorganisms to temporary soft lining materials. J Oral Sci. 2008; 50(1): $1-8$.

35. Schmalz G, Garhammer P. Biological interactions of dental cast alloys with oral tissues. Dent Mater. 2002; 18(5): 396-406.

36. Scarano A, Piattelli M, Caputi S, Favero GA, Piattelli A. Bacterial adhesion on commercially püre titanium and zirconium oxide disks: an in vivo human study. J Periodontol. 2004; 75(2): 292-6.

37. Al-Radha AS, Dymock D, Younes C, O'Sullivan D. Surface properties of titanium and zirconia dental implant materials and their effect on bacterial adhesion. J Dent. 2012; 40(2): 146-53.

38. Acosta-Torres LS, Mendieta I, Nuñez-Anita RE, Cajero-Juárez M, Castaño VM. Cytocompatible antifungal acrylic resin containing silver nanoparticles for dentures. Int J Nanomedicine. 2012; 7: 4777-86.

39. Bidar M, Naderinasab M, Talati A, Ghazvini K, As-gary S, Hadizadeh B, et al. The Effect of Different Concentrations of Chlor-hexidine Gluconate on the Antimicrobial Properties of Mineral Trioxide Aggregate and Calcium Enrich Mixture. Dent Rese J. 2012; 9: 466-71.

40. Cheng L, Weir MD, Xu HH, Kraigsley AM, Lin NJ, Lin-Gibson S, et al. Antibacterial and physical properties of calcium-phosphate and calciumfluoride nanocomposites with chlorhexidine. Dent Mater. 2012; 28(5): 573-83. 